\title{
A double-stranded 1D-coordination polymer assembled using the tetravergent ligand 1,1'-bis(4,2':6',4'-terpyridin-4'-yl)ferrocene
}

\author{
Y. Maximilian Klein, Alessandro Prescimone, Edwin C. Constable, Catherine E. \\ Housecroft* \\ Department of Chemistry, University of Basel, Spitalstrasse 51, CH 4056 Basel, Switzerland \\ Email: catherine.housecroft@unibas.ch (C.E.Housecroft)
}

\begin{abstract}
Bis(4,2':6',4"-terpyridin-4'-yl)ferrocene (1) reacts with $\mathrm{ZnCl}_{2}$ to yield a double-stranded 1D-coordination polymer $\left[\left\{\mathrm{Zn}_{2}(\mathbf{1}) \mathrm{Cl}_{4}\right\} \cdot 3 \mathrm{CHCl}_{3}\right]_{n}$. The 1,1'-functionalized ferrocene core adopts a cisoid-conformation, giving rise to a folded conformation for $\mathbf{1}$ and a double-stranded 1D-polymer chain. This contrasts with previously reported multistranded chains supported by 4,2':6',4"-terpyridine ligands in which the multiple-nature of the chain arises from multinuclear metal nodes.
\end{abstract}

Keywords: X-ray; 1D-coordination polymer; zinc; ferrocene; double-stranded chain

The use of polytopic ligands is a powerful strategy for directing the assembly of metallomacrocycles and coordination polymers and networks [1]. We have shown that $3,2^{\prime}: 6^{\prime}, 3^{\prime \prime}$ - or 4,2':6',4"-terpyridines (tpy) are versatile divergent polytopic ligands in which each terminal pyridyl ring can coordinate a different metal centre. The combination of multiple tpy domains generates new tectons [2] for the assembly of 2D-networks, interpenetrating 2D $\rightarrow$ 2D parallel interpenetrated networks, and 3D-frameworks [3,4,5]. In these examples to date, the 3,2':6',3"- or 4,2':6',4"-tpy domains are connected by a phenylene spacer; rotation about the $\mathrm{C}_{\text {phenyl }}-\mathrm{C}_{\text {tpy }}$ bonds leads to these polytopic ligands being able to act as planar or $C_{2}$ 4-connecting nodes (Scheme 1). Additional rotational freedom can be introduced by using organometallic sandwich units as connectors, the archetype of which is ferrocene [6,7]. Despite the variety of known 1,1'-ferrocenyl-centred polytopic ligands [6,7], few exhibit pyridine or polypyridine metal-binding domains. Braga et al. have investigated the coordination behaviour of 1,1'-bis(pyridin-4-yl)ferrocene, demonstrating that a cisoid-conformation is favoured leading to discrete molecular rather than polymeric assemblies [8,9]. 1,1'-Bis(pyridin-2-yl)ferrocene and its permethylated analogue act as $N, N^{\prime}$-chelates to $\mathrm{Cu}^{+}$and $\mathrm{Pd}^{2+}[10,11,12]$, or can bind two metal centres in discrete complexes [12]. Here we report the first example of a polytopic bis(4,2':6',4"terpyridine) ligand containing a 1,1'-ferrocenyl spacer and its reaction with $\mathrm{ZnCl}_{2}$ to give 
an unusual double-chain 1D-coordination polymer.

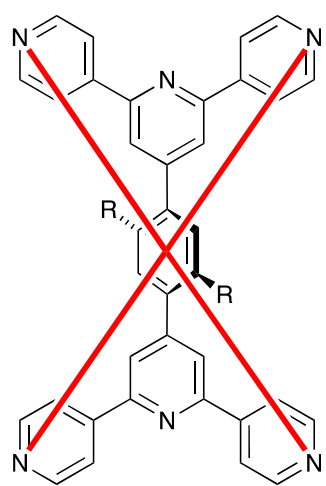

Planar node

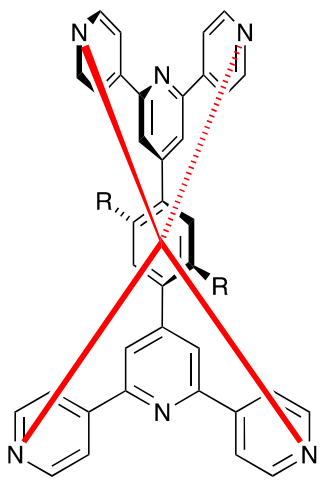

Pseudo-tetrahedral node

Scheme 1. Limiting topographies of 4-connecting nodes featuring polytopic 4,2':6',4"-tpy ligands with phenyl spacers (see references [3-5] for R).

Compound 1 (Scheme 2) was prepared according to the method reported by Wang and Hanan [13] and is poorly soluble in most organic solvents, although enough material dissolved in $\mathrm{CDCl}_{3}$ to permit a ${ }^{1} \mathrm{H}$ NMR spectrum to be recorded [14]. The ferrocenyl unit is characterized by two multiplets ( $\delta 4.85$ and $4.59 \mathrm{ppm}$ ) of equal intensity, consistent with functionalization on each cyclopentadienyl ring. Signals for the tpy domain [14] were also consistent with the structure shown in Scheme 2. In the MALDI mass spectrum, the highest mass peak envelope at $\mathrm{m} / z, 649.52$ was assigned to $[\mathrm{M}+\mathrm{H}]^{+}$.<smiles>c1ccc(-c2cc(-c3ccncc3)cc(-c3cc(-c4ccncc4)nc(-c4ccncc4)c3)c2)cc1</smiles>

Scheme 2. Structure of ligand $\mathbf{1 .}$

Red crystals of $\left[\left\{\mathrm{Zn}_{2}(\mathbf{1}) \mathrm{Cl}_{4}\right\} \cdot 3 \mathrm{CHCl}_{3}\right]_{n}$ were obtained from reaction of $\mathrm{ZnCl}_{2}$ with $\mathbf{1}$ under room temperature crystallization conditions [15]. The very poor solubility of $\mathbf{1}$ resulted in a suspension in $\mathrm{CHCl}_{3}$ rather than a solution of the free ligand being used, and insufficient bulk material of the product for powder diffraction or elemental analysis was obtained. Single-crystal structure determination [16] revealed the formation of the coordination polymer $\left[\left\{\mathrm{Zn}_{2}(\mathbf{1}) \mathrm{Cl}_{4}\right\} \cdot 3 \mathrm{CHCl}_{3}\right]_{n}$. The complex crystallizes in the monoclinic space group 
$P 2{ }_{1} / n$, and Fig. 1 shows the asymmetric unit which contains two independent $\mathrm{Zn}$ atoms (each tetrahedrally coordinated) and two halves of two ligands 1. As expected [17], the $4,2^{\prime}: 6^{\prime}, 4^{\prime \prime}$-tpy unit binds the $\mathrm{Zn}$ centres only through the outer pyridine rings. The second half of each ligand is generated by a 2-fold screw axis, with $\mathbf{1}$ adopting a cisoidconformation. Bond lengths (caption to Fig. 1) and angles in the coordination spheres of $\mathrm{Zn} 1$ and $\mathrm{Zn} 2$ and in the ferrocene unit are typical.

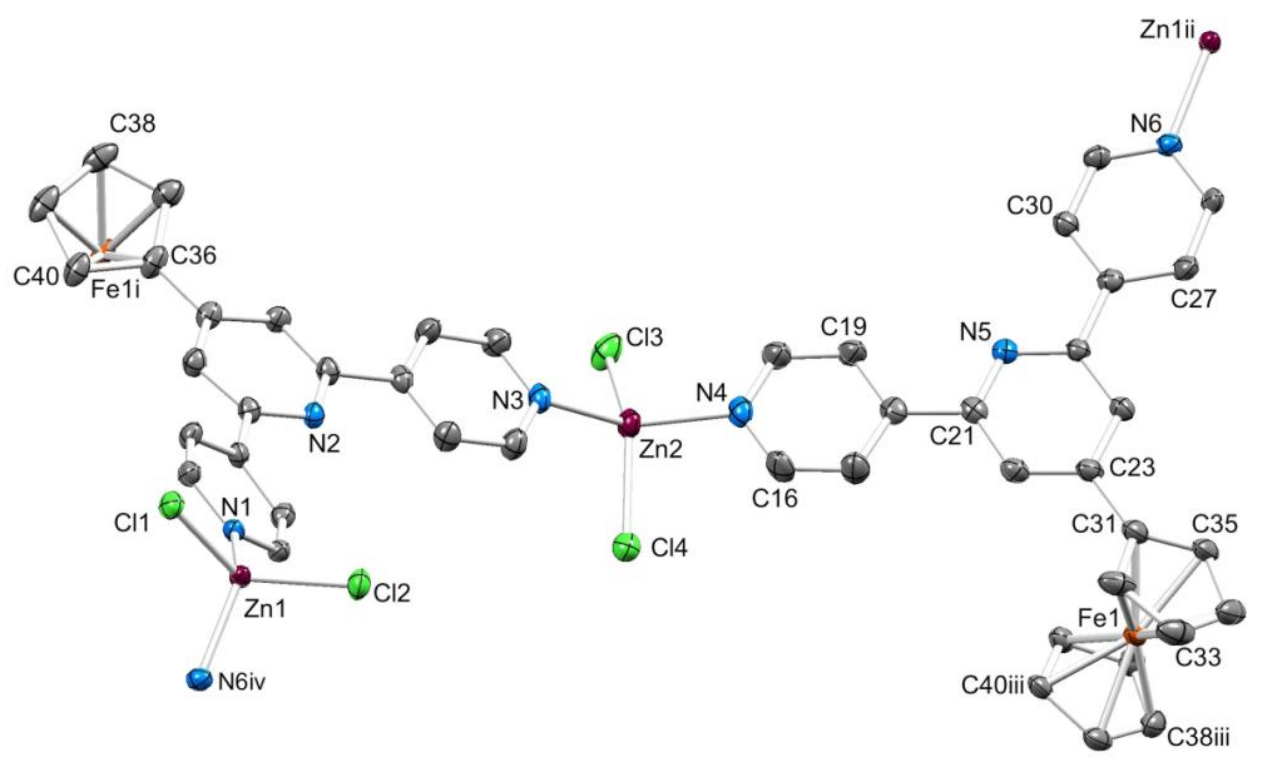

Fig. 1. The asymmetric unit in $\left[\left\{\mathrm{Zn}_{2}(\mathbf{1}) \mathrm{Cl}_{4}\right\} \cdot 3 \mathrm{CHCl}_{3}\right]_{n}$ with symmetry-generated atoms; $\mathrm{H}$ atoms and solvent molecules are omitted for clarity. Symmetry codes: $i=3 / 2-x,-1 / 2+y, 3 / 2-$ $\mathrm{z}$; ii $=\mathrm{x}, 1+\mathrm{y}, \mathrm{z}$; iii $=3 / 2-\mathrm{x}, 1 / 2+\mathrm{y}, \frac{3}{2}-\mathrm{z}$; iv $=\mathrm{x},-1+\mathrm{y}$, z. Selected bond distances: $\mathrm{Zn} 1-\mathrm{N} 6 \mathrm{iv}$ $=2.042(4), \mathrm{Zn} 1-\mathrm{N} 1=2.035(4), \mathrm{Zn} 1-\mathrm{Cl} 1=2.2453(13), \mathrm{Zn} 1-\mathrm{Cl} 2=2.2435(13), \mathrm{Zn} 2-\mathrm{N} 3=$ 2.076(4), Zn2-N4 = 2.079(4), Zn2-Cl3 = 2.2499(15), Zn2-Cl4 = 2.2708(14) Å.

The cisoid-conformation of $\mathbf{1}$ results in a double-stranded chain, with tpy units in the same ligand lying over the top of each other (Fig. 2). However, each tpy domain is significantly bowed, and only the central pyridine rings of the two tpy units are able to engage in faceto-face $\pi$-stacking (centroid...centroid separation $=3.60 \AA$ and centroid....ring-plane distance $=3.35 \AA$ ). Double-stranded chains have previously been observed for $\left[\mathrm{Cd}_{2}(\mathrm{OAc})_{4}\left(4^{\prime}-(\text { biphenyl-4-yl)-4,2':6',4"-tpy })_{2}\right]_{n}[18]\right.$, but in this case, the origin of the double-strands is the presence of dinuclear $\left\{\mathrm{Cd}_{2}(\mathrm{OAc})_{4}\right\}$ nodes, each node binding four separate 4,2':6',4"-tpy ligands. Similarly, in $\left[\mathrm{Mn}_{3}(\mathrm{OAc})_{6}\left(4^{\prime}-\left(4-\mathrm{BrC}_{6} \mathrm{H}_{4}\right)-4,2^{\prime}: 6 ', 4 "-\text { tpy }\right)_{3}\right]_{n}$, trinuclear $\left\{\mathrm{Mn}_{3}(\mathrm{OAc})_{6}\right\}$ nodes gives rise to a triple-stranded chain [19], and in

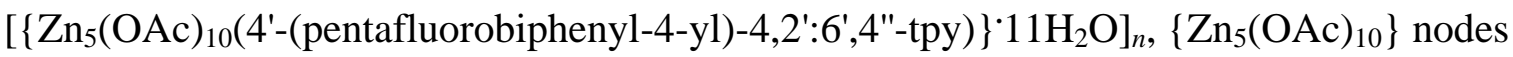
lead to an unusual quadruple-stranded chain [20]. The assembly of $\left[\left\{\mathrm{Zn}_{2}(\mathbf{1}) \mathrm{Cl}_{4}\right\} \cdot 3 \mathrm{CHCl}_{3}\right]_{n}$ is, to the best of our knowledge, the first example of a 1D-coordination polymer with 
$4,2^{\prime}: 6^{\prime}, 4^{\prime \prime}$-tpy ligand linkers in which a bis $\left(4,2^{\prime}: 6^{\prime}, 4^{\prime \prime}\right.$-tpy) presents a folded conformation to generate a double-stranded chain. The closest $\mathrm{Zn}$...Zn separation across the chain is 4.678(1) $\AA$. Atoms $\mathrm{Cl} 3$ and $\mathrm{Cl} 4$ of one $\mathrm{ZnCl}_{2}$ unit face atom $\mathrm{Zn} 1$ across the chain (Fig. 2) but the $\mathrm{Zn} 1$...Cl3 and Zn1...Cl4 distances of 4.291(2) and 4.155(2) $\AA$ are too long to be considered meaningful interactions.

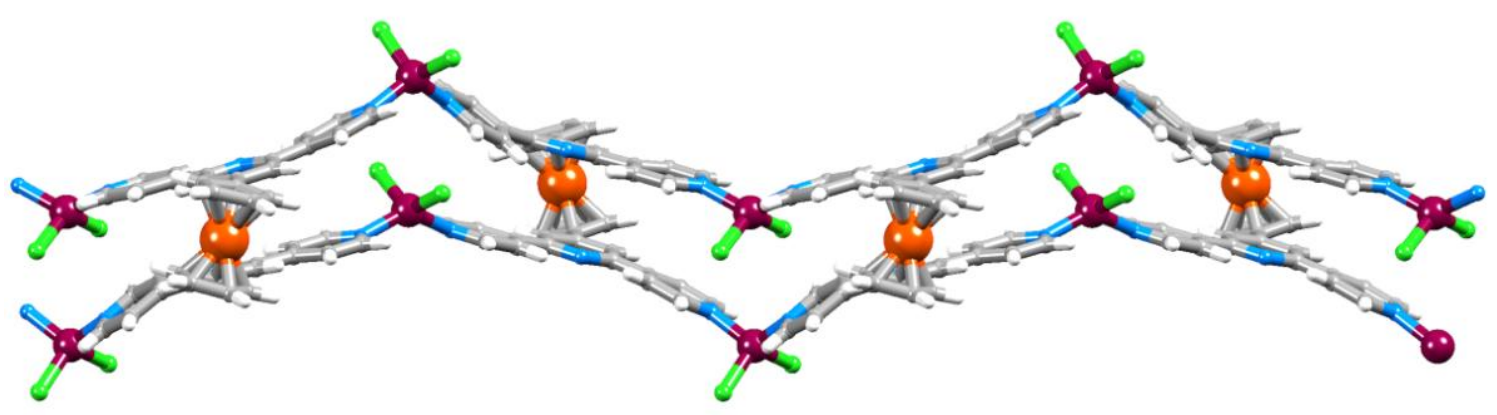

Fig. 2. Part of one chain in $\left[\left\{\mathrm{Zn}_{2}(\mathbf{1}) \mathrm{Cl}_{4}\right\} \cdot 3 \mathrm{CHCl}_{3}\right]_{n}$.

The double-stranded chains propagate along the $b$-axis, with their zig-zag form (Fig. 3) arising from the V-shape of the 4,2':6',4"-tpy domains. Adjacent chains nest together forming sheets, but, in contrast to related structures $\left[{ }^{17},{ }^{18},{ }^{19},{ }^{20}, 21\right.$, ], there are no close contacts between neighbouring chains (coloured blue in Fig. 3a). This results in void space which is occupied by $\mathrm{CHCl}_{3}$ molecules.

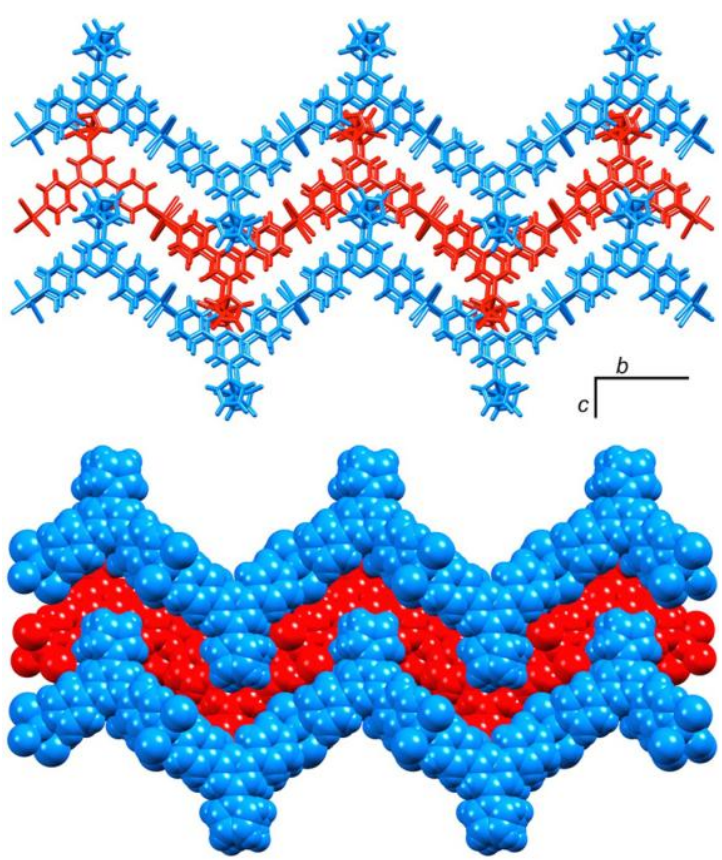

Fig. 3. Stick and space-filling representations of double-stranded chains in $\left[\left\{\mathrm{Zn}_{2}(\mathbf{1}) \mathrm{Cl}_{4}\right\} \cdot 3 \mathrm{CHCl}_{3}\right]_{n}$ to illustrate packing. The structure is viewed down the $a$-axis, and chains coloured blue pack into sheets in the $b c$-plane. Solvent molecules are omitted. 
In conclusion, the ferrocenyl-centred polytopic ligand $\mathbf{1}$ exhibits a folded conformation in the $1 \mathrm{D}$-coordination polymer $\left[\left\{\mathrm{Zn}_{2}(\mathbf{1}) \mathrm{Cl}_{4}\right\} \cdot 3 \mathrm{CHCl}_{3}\right]_{n}$ leading to a double-stranded zigzag chain. This contrasts with previously reported multiply-stranded chains containing $4,2^{\prime}: 6^{\prime}, 4^{\prime \prime}$-terpyridine ligands in which the nature of the chain arises from di-, tri- or pentanuclear metal nodes.

\section{Acknowledgements}

We thank the Swiss National Science Foundation (Grant number 200020_144500) and the University of Basel for support.

\section{References}

1 E. C. Constable and C.E. Housecroft in Comprehensive Inorganic Chemistry II, eds. J. Reedijk and K. R. Poeppelmeier, Elsevier, Oxford, 2013, vol. 8, Chapter 8.01, p. 1.

2 M. W. Hosseini, Acc. Chem. Res. 38 (2005) 313.

3 E. C. Constable, C. E. Housecroft, S. Vujovic, J. A. Zampese, CrystEngComm 16 (2014) 3494.

4 S. Vujovic, E. C. Constable, C. E. Housecroft, C. D. Morris, M. Neuburger, A. Prescimone, Polyhedron 92 (2015) 77.

5 Y. M. Klein, E. C. Constable, C. E. Housecroft, A. Prescimone, CrystEngComm 17 (2015) 2070.

6 R. Horikoshi, Coord. Chem. Rev. 257 (2013) 621.

7 R. Horikoshi, T. Mochida, Eur. J. Inorg. Chem. (2010) 5355.

8 D. Braga, M. Polito, D. D'Addario, E. Tagliavini, D.M. Proserpio, F. Grepioni, J.W. Steed, Organometallics 22 (2003) 4532.

9 D. Braga, M. Polito, M. Bracaccini, D. D'Addario, E. Tagliavini, D.M. Proserpio, F. Grepioni, Chem.Commun. (2002) 1080.

10 U. Siemeling, U. Vorfeld, B. Neumann, H.-G. Stammler, Chem. Comm. (1997) 1723.

11 B. Neumann, U. Siemeling, H.-G. Stammler, U. Vorfeld, J.G.P. Delis, P.W.N.M. van Leeuwen, K. Vrieze, J. Fraanje, K. Goubitz, F. Fabrizi de Bianni, P. Zanello, J. Chem. Soc., Dalton Trans. (1997) 4705.

12 J.G.P. Delis, P.W.N.M. van Leeuwen, K. Vrieze, N. Veldman, A.L. Spek, J. Fraanje, K. Goubitz, J. organometa. Chem. 514 (1996) 125.

13 J. Wang, G.S. Hanan, Synlett (2005) 1251.

14 1,1'-Ferrocenedicarboxaldehyde $(0.20 \mathrm{~g}, 0.83 \mathrm{mmol})$ was dissolved in EtOH (70 $\mathrm{mL})$. 4-Acetylpyridine $(0.45 \mathrm{~g}, 3.63 \mathrm{mmol})$ and $\mathrm{KOH}(0.23 \mathrm{~g}, 4.13 \mathrm{mmol})$ were added to the solution. Aqueous $\mathrm{NH}_{3}(32 \%, 6.36 \mathrm{~mL})$ was slowly added to the reaction mixture which was then stirred at room temperature overnight. The solid that formed was collected by filtration, washed with $\mathrm{EtOH}(3 \times 20 \mathrm{~mL})$ and $\mathrm{H}_{2} \mathrm{O}(3$ 
$\times 20 \mathrm{~mL})$ and dried in vacuo. Compound 1 was isolated as a red powder $(0.24 \mathrm{~g}$, $0.37 \mathrm{mmol}, 44.8 \%)$. Decomp > 300 ${ }^{\circ} \mathrm{C} .{ }^{1} \mathrm{H} \mathrm{NMR}\left(500 \mathrm{MHz}, \mathrm{CDCl}_{3}, 298 \mathrm{~K}\right) \delta / \mathrm{ppm}$ $8.60\left(\mathrm{~m}, 4 \mathrm{H}, \mathrm{H}^{\mathrm{A} 2}\right), 7.67\left(\mathrm{~m}, 4 \mathrm{H}, \mathrm{H}^{\mathrm{A} 3}\right), 7.41\left(\mathrm{~m}, 2 \mathrm{H}, \mathrm{H}^{\mathrm{B} 3}\right), 4.85\left(\mathrm{~m}, 2 \mathrm{H}, \mathrm{H}^{\mathrm{Cp}}\right), 4.59$ $\left(\mathrm{m}, 2 \mathrm{H}, \mathrm{H}^{\mathrm{Cp}}\right)$. IR $\left(\mathrm{v} / \mathrm{cm}^{-1}\right) 3032(\mathrm{w}), 1612(\mathrm{~m}), 1596(\mathrm{~s}), 1559(\mathrm{~m}), 1541(\mathrm{~m}), 1431$ (m), $1411(\mathrm{~m}), 1398(\mathrm{~m}), 1261(\mathrm{w}), 1226(\mathrm{w}), 1067(\mathrm{w}), 1036(\mathrm{w}), 994(\mathrm{~m}), 892$ (w), $827(\mathrm{~s}), 764(\mathrm{w}), 741(\mathrm{w}), 679(\mathrm{w}), 649(\mathrm{~m}), 629(\mathrm{~s}), 597(\mathrm{w}), 570(\mathrm{~m}), 508$ $(\mathrm{m}), 475$ (m). MALDI-MS ( $\alpha$-cyano-4-hydroxycinnamic acid matrix) $\mathrm{m} / \mathrm{z} 649.52$ $[\mathrm{M}+\mathrm{H}]^{+}$(calc. 649.18). Found C 70.44, H 4.65, N 12.38; calculated for $\mathrm{C}_{40} \mathrm{H}_{28} \mathrm{FeN}_{6} \cdot 2 \mathrm{H}_{2} \mathrm{O}$ C 70.18, $\mathrm{H} 4.71, \mathrm{~N} 12.28$.

15 A solution of $\mathrm{ZnCl}_{2}(1.36 \mathrm{mg}, 0.01 \mathrm{mmol})$ in $\mathrm{MeOH}(8 \mathrm{~mL})$ was layered over a suspension of 1 (6.49 mg, $0.01 \mathrm{mmol})$ in $\mathrm{CHCl}_{3}(5 \mathrm{~mL})$. Red crystals of $\left[\left\{\mathrm{Zn}_{2}(\mathbf{1}) \mathrm{Cl}_{4}\right\} \cdot 3 \mathrm{CHCl}_{3}\right]_{n}(0.2 \mathrm{mg}, 0.156 \mu \mathrm{mol}, 1.6 \%$ based on $\mathbf{1})$ were obtained after 2-4 weeks. Insufficient amount of crystalline material was obtained for bulk analysis.

16 Crystal data for $\left[\left\{\mathrm{Zn}_{2}(\mathbf{1}) \mathrm{Cl}_{4}\right\} \cdot 3 \mathrm{CHCl}_{3}\right]_{n}: \mathrm{C}_{43} \mathrm{H}_{31} \mathrm{Cl}_{13} \mathrm{FeN}_{6} \mathrm{Zn}_{2}, M=1279.25$, red block, monoclinic, space group $P 2{ }_{1} / n, a=13.5721(11), b=23.659(2), c=$ 15.0438(12) $\AA, \beta=94.479(3)^{\mathrm{o}}, U=4815.8(7) \AA^{3}, Z=4, D_{c}=1.764 \mathrm{Mg} \mathrm{m}^{-3}, \mu(\mathrm{Cu}-$ $\mathrm{K} \alpha)=10.517 \mathrm{~mm}^{-1}, T=123 \mathrm{~K}$. Total 49487 reflections, 8941 unique, $R_{\text {int }}=0.027$. Refinement of 8630 reflections (586 parameters) with $I>2 \sigma(I)$ converged at final $R 1=0.0749(R 1$ all data $=0.0765), w R 2=0.1882(w R 2$ all data $=0.1890)$, gof $=$ 0.9829 .

17 C. E. Housecroft, Dalton Trans. 43 (2014) 6594.

18 E. C. Constable, C. E. Housecroft, M. Neuburger, J. Schönle, S. Vujovic, J. A. Zampese, Polyhedron 62 (2013) 120.

19 E. C. Constable, G. Zhang, E. Coronado, C. E. Housecroft, M. Neuburger, CrystEngComm 12 (2010) 2139.

20 E. C. Constable, C. E. Housecroft, S. Vujovic, J. A. Zampese, A. Crochet, S. R. Batten, CrystEngComm 15 (2013) 10068.

21 L. Li, Y.Z. Zhang, C. Yang, E. Liu, J.A. Golen and G. Zhang, Polyhedron 105 (2016) 115. 
GRABS

Bis(4,2':6',4"-terpyridin-4'-yl)-1,1'-ferrocene (1) adopts a cisoid-conformation when coordinated to zinc(II) and forms a double-stranded 1D-coordination polymer $\left[\left\{\mathrm{Zn}_{2}(\mathbf{1}) \mathrm{Cl}_{4}\right\} \cdot 3 \mathrm{CHCl}_{3}\right]_{n}$. 


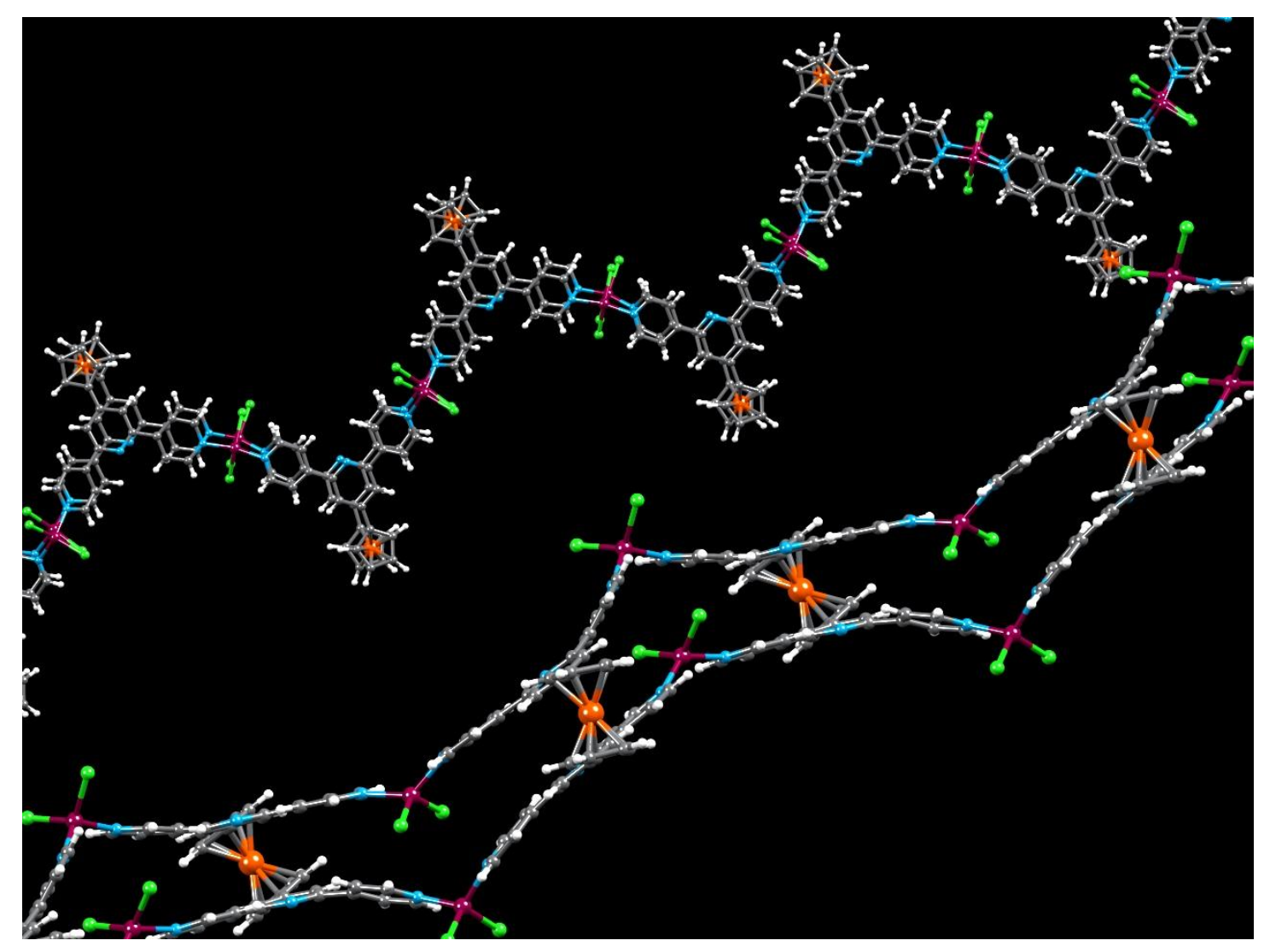

